\title{
IMPLICAÇÕES DE UM CENTRO DE SERVIÇOS COMPARTILHADOS NA CONTABILIDADE GERENCIAL: UMA ABORDAGEM INSTITUCIONAL ${ }^{1}$
}

\author{
Ilse Maria Beuren ${ }^{2}$ \\ Luciane Regina Braçaroto de Souza ${ }^{3}$ \\ Helena de Oliveira Leite Feuser ${ }^{4}$
}

http://dx.doi.org/10.1590/1413-2311.162.61627

\begin{abstract}
RESUMO
Este estudo analisa, sob a abordagem institucional, as implicações da implantação de um Centro de Serviços Compartilhados (CSC) nas funções da Contabilidade Gerencial. Para tal, foi realizada uma pesquisa de natureza descritiva com abordagem qualitativa, a partir de um estudo de caso em empresa situada na região Sul do Brasil, constituída sob a forma de um CSC. Sob a lente da Teoria Institucional, consubstanciada no modelo proposto por Burns e Scapens (2000), foi analisada a institucionalização de regras e rotinas na Contabilidade Gerencial da empresa. Os resultados da pesquisa mostram que a implantação do CSC teve implicações diretas e indiretas nas funções da Contabilidade Gerencial, visto que foi necessário alterar várias de suas funções, atividades, divisionalizações, inclusive profissionais, portanto, uma reestruturação ampla e profunda em todo o setor. Quanto às dicotomias de mudanças ocorridas com a implantação do CSC, foram observadas mais mudanças formais do que informais, evolucionárias do que revolucionárias e progressivas do que regressivas nas funções da Contabilidade Gerencial. Conclui-se com base na análise triangulada dos dados coletados, que a implantação do CSC na empresa pesquisada teve implicações significativas na estrutura organizacional e na natureza das funções da Contabilidade Gerencial, as quais resultaram na institucionalização de novas regras e rotinas nos moldes preconizados por Burns e Scapens (2000). Os resultados do estudo contribuem para o desenvolvimento de novos papéis na Contabilidade Gerencial, sob o argumento que o modelo de CSC gerou novas regras e rotinas em toda a corporação, com implicações diretas e indiretas nos papéis gerenciais institucionalizados.
\end{abstract}

Palavras-Chave: Centro de Serviços Compartilhados. Contabilidade Gerencial. Teoria Institucional.

\section{IMPLICATIONS OF A SHARED SERVICE CENTER IN MANAGEMENT ACCOUNTING: AN INSTITUTIONAL APPROACH}

\footnotetext{
ABSTRACT

${ }^{1}$ Recebido em 14/01/2016; aprovado em 02/08/2017.

${ }^{2}$ Universidade Federal de Santa Catarina - ilse.beuren@gmail.com.

${ }^{3}$ Universidade Federal do Paraná - lu_bracaroto@ hotmail.com.

${ }^{4}$ Universidade Federal do Paraná - helenaleite2@ gmail.com.
} 
This study analyzes under the institutional approach, the implications of the implementation of a Shared Services Center (SSC) in the functions of management accounting. To do so, a research of descriptive nature was carried out with qualitative approach, from a case study of a company located in southern Brazil, operating with a SSC. Through the lens of the Institutional Theory, based on the model proposed by Burns and Scapens (2000), the institutionalization of rules and routines in the management accounting of the company was analyzed. The survey results show that the implementations of the SSC had direct and indirect implications in the functions of the Management Accounting, as it was necessary to change several of its functions, activities, divisionalisations, including professionals, therefore, a broad and deep restructuring in the whole the area. Regarding the dichotomies of changes that happened with the implementation of the SSC, there were more formal than informal changes, evolutionary than revolutionary, and progressive than regressive in the functions of Management Accounting. It is concluded, based on the triangulated data analysis, that the implementations of the SSC in the company studied had significant implications in the organizational structure and in the nature of the functions of the Management Accounting, which resulted in the institutionalization of new rules and routines, as preconized by Burns and Scapens (2000). The results of the study contribute to the development of new roles in Management Accounting, based on the argument that the SSC model created new rules and routines throughout the corporation, with direct and indirect implications in the institutionalized managerial roles.

Keywords: Shared Services Center. Management Accounting. Institutional Theory.

\section{IMPLICACIONES DE UN CENTRO DE SERVICIO COMPARTIDO EN LA CONTABILIDAD DE GESTIÓN: UN ENFOQUE INSTITUCIONAL}

\section{RESUMEN}

Este estudio analiza, bajo el enfoque institucional, las implicaciones de la implementación de un Centro de Servicios Compartidos (CSC) en las funciones de la contabilidad de gestión. Para tal, se llevó a cabo investigación descriptiva con enfoque cualitativo a partir de un estudio de caso en una empresa situada en la región Sur de Brasil, organizada en forma de un CSC. A través de la lente de la Teoría Institucional, basado en el modelo propuesto por Burns y Scapens (2000), se analizó la institucionalización de reglas y rutinas en la contabilidad de gestión de la empresa. Los resultados de la encuesta muestran que la implementación de lo CSC tuvo consecuencias directas e indirectas en las funciones de la contabilidad de gestión, ya que era necesario cambiar varias de sus funciones, actividades, divisionalisationes, incluso profesionales, por lo tanto, una reestructuración amplia y profunda en todo el sector. Cuanto a las dicotomías de cambios ocurridos con la implementación del CSC, se observaron más cambios formales que informales, evolucionarios que revolucionarios, y progresivos que regresivos en las funciones de la contabilidad de gestión. Se concluye basado en el análisis de datos triangulada, que la implementación del CSC en la empresa investigada tiene implicaciones importantes en la estructura organizacional y en la naturaleza de las funciones de la contabilidad de gestión, las cuáles resultaran en la institucionalización de las nuevas reglas y rutinas en la manera recomendada por Burns y Scapens (2000). Los resultados del estudio contribuyen al desarrollo de nuevos papeles en la contabilidad de gestión, con el argumento de que el modelo de CSC creó nuevas reglas y rutinas en toda la empresa, con 
implicaciones directas e indirectas en los papeles de gestión institucionalizados.

Palabras-Clave: Centro de Servicios Compartidos. Contabilidad de Gestión. Teoría Institucional.

\section{INTRODUÇÃO}

Em um cenário competitivo, o aperfeiçoamento de processos e a redução de custos, com vistas no aumento da eficiência, são fundamentais para assegurar o desenvolvimento das empresas (SUM; PAULA, 2011). Quinn, Cooke e Kris (2000) apontam que 25\% a 30\% dos custos de uma empresa estão relacionados aos serviços de suporte. Nesta perspectiva, uma forma de reduzir custos relativos aos processos é a implantação de um Centro de Serviços Compartilhados (CSC). A busca contínua de redução de custos, aliada à necessidade de melhorias, padronizações e automatizações dos processos, mantendo alto índice de satisfação de clientes, constituem-se alvos dos CSCs (PORTULHAK et al., 2013).

A implantação de um CSC representa uma transformação na estrutura organizacional, uma vez que a empresa transfere das suas unidades de negócios atividades de apoio e passa a efetuá-las em outro local (SCHUMAN; HARMER; DUNLEAVY, 1999). Embora a implantação de um CSC seja uma prática cada vez mais utilizada pelas empresas (SCHUMAN; HARMER; DUNLEAVY, 1999; RAMOS, 2005; MARTINS; AMARAL, 2008), sua adoção por empresas brasileiras é relativamente recente. Da mesma forma, o material bibliográfico sobre este tema ainda é escasso no Brasil (PORTULHAK et al., 2013).

Com o intuito de compreender as transformações nas estruturas organizacionais, Burns e Scapens (2000) desenvolveram uma proposição para analisar os processos de mudança que ocorrem ao longo do tempo, no campo institucional das organizações. Clegg e Hardy (2006) argumentam que a Teoria Institucional se mostra promissora nesta temática, ao proporcionar elementos que permitem explicar os fenômenos ocorridos, por meio da compreensão de como as estruturas e ações organizacionais tornam-se legitimadas e quais as consequências nos resultados planejados para as organizações.

Herbert e Seal (2012) basearam-se no modelo proposto por Burns e Scapens (2000), fundamentado na Teoria Institucional, para analisar mudanças nas funções da Contabilidade Gerencial em uma empresa do setor elétrico do Reino Unido. Constataram que a implantação do CSC provocou mudanças significativas na estrutura organizacional da empresa em diferentes aspectos, inclusive no desenvolvimento da Contabilidade Gerencial. Como o 
processamento de transações foi transferido para o CSC, os contadores gerenciais das unidades de negócios puderam se concentrar em fornecer suporte à tomada de decisões dos gestores, além da oportunidade de desempenhar novos papéis.

Embora Herbert e Seal (2012) tenham observado um cenário favorável para que os contadores gerenciais das unidades de negócios se concentrem mais no fornecimento de informações de suporte à tomada de decisões dos gestores a partir da implantação de um CSC na empresa pesquisada, ainda se observa uma lacuna quanto ao desenvolvimento das funções da Contabilidade Gerencial neste caso. As dicotomias nos processos de mudanças, como formal e informal, revolucionária e evolucionária, progressiva e regressiva, conforme proposto por Burns e Scapens (2000), podem se reproduzir e se institucionalizar de diferentes formas nas funções da Contabilidade Gerencial em cada ambiente sob análise.

Com base no exposto, a questão que norteia esta pesquisa é: Quais são as implicações, sob a abordagem institucional, da implantação de um CSC nas funções da Contabilidade Gerencial? Desta forma, o objetivo deste estudo é analisar, sob a abordagem institucional, as implicações da implantação de um Centro de Serviços Compartilhados (CSC) nas funções da Contabilidade Gerencial. O estudo pauta-se no modelo proposto por Burns e Scapens (2000) para analisar a institucionalização de regras e rotinas na Contabilidade Gerencial, decorrentes da implantação de um CSC na empresa objeto de estudo, baseando-se na análise das dicotomias de mudanças: formal versus informal, revolucionária versus evolucionária e regressiva versus progressiva.

A contribuição deste estudo está no pressuposto de que o campo do CSC ainda é relativamente novo e seu desenvolvimento abrange uma variedade de formas organizacionais e padrões de implantação (HERBERT; SEAL, 2012). Assim, a contribuição dessa pesquisa está em investigar as implicações da implantação do CSC nas funções da Contabilidade Gerencial de uma empresa que migrou para esta configuração de estrutura organizacional. Analisar a institucionalização das mudanças nas funções da Contabilidade Gerencial em virtude da implantação de um CSC pode contribuir para o entendimento das alterações nas regras e rotinas e seus reflexos na otimização dos processos e na qualidade da informação fornecida aos gestores das unidades de negócios da organização.

O estudo baseou-se no construto da pesquisa de Herbert e Seal (2012) aplicado na análise das mudanças nas funções da Contabilidade Gerencial com a implantação de um CSC. Essa afiliação teórico-metodológica decorre das fontes escassas de pesquisa sobre o assunto no Brasil. Presume-se que questões locais podem ser investigadas e exploradas, ao capturar experiências e informações sobre situações ocorridas em outra organização. Segundo a 
pesquisa realizada por Deloitte (2009), a falta de conhecimento sobre o modo de operação de um CSC é considerada a principal barreira existente para as empresas brasileiras que ainda não optaram por implantá-lo. Assim como o estudo de Portulhak et al. (2013), este pode incrementar o corpo teórico sobre o tema no Brasil e no mundo, com ênfase nos reflexos da implantação do CSC nas funções da Contabilidade Gerencial.

\section{REFERENCIAL TEÓRICO}

No referencial teórico, inicialmente faz-se uma incursão no processo de análise de mudanças nas funções da Contabilidade Gerencial, sob a lente da Teoria Institucional. Na sequência discorre-se sobre a aplicação do construto de mudanças no campo institucional de uma organização, elucidando o estudo de Herbert e Seal (2012), que foi baseado no modelo de Burns e Scapens (2000), fundamentado na Teoria Institucional, para analisar mudanças nas funções da Contabilidade Gerencial. Por fim, abordam-se as características de um CSC e as implicações decorrentes de mudanças na estrutura organizacional.

\subsection{MUDANÇAS NA CONTABILIDADE GERENCIAL SOB A LENTE DA TEORIA INSTITUCIONAL}

Características do ambiente social e empresarial impactadas pela implantação de um CSC podem ser indutoras de processos de mudanças. Com a implantação de um CSC ocorrem mudanças na estrutura da organização, o que implica na implementação de processos de mudanças na sua forma de atuação, no seu modelo de gestão, nos seus instrumentos gerenciais e, portanto, na Contabilidade Gerencial (GUERREIRO; FREZATTI; CASADO, 2006). Herbert e Seal (2012) advertem que na implantação de um CSC, as funções préexistentes também sofrem alterações, como é o caso do contador gerencial.

Burns e Scapens (2000) aduzem que, embora alguns pesquisadores argumentem que a natureza fundamental dos sistemas e práticas de Contabilidade Gerencial não mude, há evidências de que o uso da contabilidade no processo de gestão tem mudado. Os gestores agora parecem usar os sistemas contábeis e os relatórios financeiros de forma mais flexível, utilizando-os junto a uma ampla gama de outros indicadores de resultados, tanto financeiros como não financeiros. Assim, esses autores salientam que o estudo dos processos de mudança da Contabilidade Gerencial requer a conceptualização das formas pelas quais novas práticas contábeis evoluem ao longo do tempo. 
Neste sentido, a Teoria Institucional pode fornecer importantes contribuições à gestão das organizações, ao ter como premissa básica que os processos organizacionais resultam não apenas da ação humana, mas igualmente das interações com o contexto cultural e político (FACHIN; MENDONÇA, 2003). Dillard, Rigsby e Goodman (2004) defendem que o processo de institucionalização passa por três níveis de relações sócio-históricas de forma recursiva em cascata, o nível econômico e político (EP); o nível do campo organizacional (CO); e o nível organizacional (nível intra-organizacional). Todos eles foram concebidos e analisados neste estudo sob a ótica da Teoria Institucional.

Com um olhar mais específico, Burns (2000) explica que a vertente da Teoria Institucional que fundamenta estudos analíticos de mudanças nas rotinas da Contabilidade Gerencial é a Velha Economia Institucional (Old Institutional Economics - OIE). Ela busca explicar o porquê e como as coisas se tornam o que elas são ou não são com o passar do tempo. Sob esta lente, Burns e Scapens (2000) advertem que, em muitas organizações, os sistemas e práticas da Contabilidade Gerencial constituem regras e rotinas estáveis. Explicam que as regras compreendem os sistemas de contabilidade gerencial formais, reportadas em manuais de procedimentos, enquanto que as rotinas são práticas contábeis atualmente em uso.

Com esse pressuposto, Burns e Scapens (2000) desenvolveram um construto para conceptualizar a mudança na Contabilidade Gerencial fundamentado na Teoria Institucional, que não somente reforce a estabilidade inserida no comportamento baseado nas regras e nas rotinas dos sistemas e práticas organizacionais, mas que também reconheça que as regras e rotinas podem mudar. O construto desenvolvido por Burns e Scapens (2000) refere-se aos processos de mudanças que ocorrem ao longo do tempo no campo institucional das organizações (Figura 1).

A parte superior da Figura 1 representa o campo institucional, enquanto que a parte inferior representa o campo de ação. Ambos os campos estão em processo de interação contínua, dentro de um processo cumulativo de mudança ao longo do tempo, representado pelas linhas sólidas na parte superior e inferior da ilustração. A parte central indica a forma pela qual as rotinas e regras agem como protocolos que conectam o campo institucional e o campo da ação. As rotinas e regras estão dentro de um processo cumulativo de mudança. No entanto, de tempos em tempos, novas rotinas e regras podem ser introduzidas.

Figura 1 - Modelo de mudança organizacional 


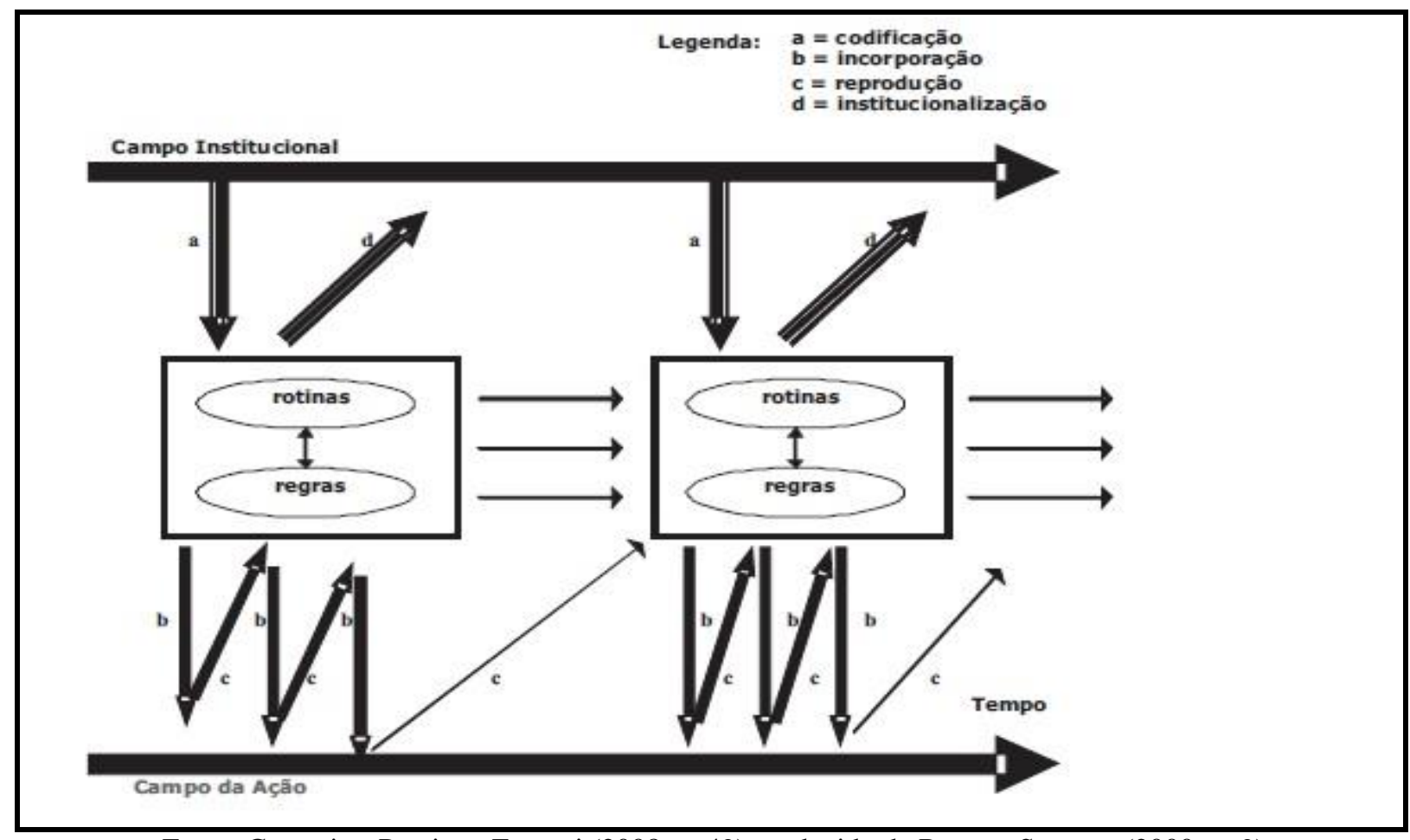

Fonte: Guerreiro, Pereira e Frezatti (2008, p. 49), traduzido de Burns e Scapens (2000, p. 9).

Burns e Scapens (2000) explicam que o primeiro passo (seta a) representa a codificação dos princípios institucionais em regras e rotinas. Este processo toma por base as pressuposições tidas como certas (taken-for-granted), que englobam os princípios institucionais, pela sua concretização nos significados, valores e poderes existentes. $\mathrm{O}$ segundo passo (seta b) envolve a incorporação dessas regras e rotinas. Este processo envolve uma escolha consciente, porém resulta do monitoramento reflexivo e da aplicação do conhecimento tácito sobre como as coisas devem ser feitas. O terceiro passo (seta c) acontece à medida que a repetição do comportamento leva à reprodução das regras e rotinas. E o último passo (seta d) é a institucionalização das regras e rotinas que vêm sendo reproduzidas.

Após a institucionalização das regras e rotinas é possível analisar as mudanças ocorridas nas unidades. Para Burns e Scapens (2000), mudanças específicas na Contabilidade Gerencial podem ser revolucionárias, envolvendo mudanças radicais das rotinas existentes e questionando as instituições existentes. Mesmo nestes casos, o processo de mudança será influenciado pelas rotinas e instituições existentes. Uma mudança revolucionária é mais provável como resultado de uma mudança externa, por exemplo, uma aquisição, recessão econômica, colapso de mercado. No entanto, a resposta a estes eventos provavelmente será determinada pelo contexto organizacional, incluindo suas rotinas e instituições.

Burns e Scapens (2000) destacam três dicotomias que fornecem formas de classificar e distinguir entre diferentes tipos de processos de mudança: (i) a mudança formal versus a 
informal; (ii) a mudança revolucionária versus evolucionária; e (iii) a mudança progressiva versus a regressiva. A mudança formal acontece pelo desenho consciente, normalmente pela introdução de novas regras e/ou com ações de um indivíduo. A mudança informal ocorre em um nível mais tácito, na medida em que novas rotinas se adaptam ao longo do tempo às mudanças nas condições operacionais (BURNS; SCAPENS, 2000). É razoável esperar que a mudança formal da Contabilidade Gerencial, como, por exemplo, a implementação de novos sistemas e técnicas, seja mais direcionada para a busca por mudanças nas formas de pensar, que são incorporadas nas rotinas da Contabilidade Gerencial (BERDEJO, 2009).

A mudança revolucionária envolve uma interrupção substancial nas regras e instituições existentes, enquanto que a mudança evolucionária é incremental, com uma interrupção menor nas rotinas e instituições existentes (BURNS; SCAPENS, 2000). A mudança progressiva descreve a substituição do comportamento cerimonial pelo comportamento instrumental, visto que o comportamento cerimonial surge a partir de um sistema de valores, que estabelece uma diferença entre seres humanos e preserva a estrutura de poder existente. Já o comportamento instrumental surge a partir do sistema de valores, que aplica o melhor conhecimento e tecnologia disponíveis aos problemas e para melhorar os relacionamentos. A mudança regressiva descreve o comportamento que reforma um predomínio cerimonial, restringindo, portanto, uma mudança institucional (BERDEJO, 2009).

Embora favorável à ideia do modelo desenvolvido por Burns e Scapens (2000), Dillard, Rigsby e Goodman (2004) apresentaram algumas críticas e propostas para o desenvolvimento do modelo. Argumentam que o modelo de Burns e Scapens (2000) oferece insights com base na institucionalização no nível organizacional, e este modelo precisaria ser definido dentro do contexto de uma teoria multi-camadas. Dillard, Rigsby e Goodman (2004) defendem que o processo de institucionalização passa por três níveis de relações sóciohistóricas de forma recursiva em cascata, a saber: nível econômico e político (EP); nível do campo organizacional (CO); e nível organizacional (nível intra-organizacional).

O primeiro nível, EP, estabelece normas e práticas mais gerais e mais amplamente aceitas, sob a influência de critérios simbólicos politicamente desenvolvidos, como princípios contábeis, leis e regulamentos (HOPPER; MAJOR, 2007). O segundo nível, CO, abrange as configurações socioeconômicas, como grupos industriais, entidades profissionais e consultores (DILLARD; RIGSBY; GOODMAN, 2004). O terceiro nível, intraorganizacional, representa a empresa e seus sistemas e regras internas e rotinas (BURNS; SCAPENS, 2000). Todavia, como já exposto por Dillard, Rigsby e Goodman (2004), trata-se de uma proposta para o desenvolvimento do modelo de Burns e Scapens (2000). 
Apesar das críticas deferidas por Dillard, Rigsby e Goodman (2004) ao modelo proposto por Burns e Scapens (2000), pelo fato dele não considerar os níveis de relações sócio-históricas de forma recursiva em cascata, Herbert e Seal (2012) adotaram-no em sua pesquisa para analisar a institucionalização de hábitos e rotinas na Contabilidade Gerencial com as mudanças advindas da implantação de um CSC em uma empresa do setor elétrico do Reino Unido. Os passos detalhados na proposição de Burns e Scapens (2000) mostraram-se capazes de contribuir para a análise da institucionalização de mudanças ocorridas nas funções da Contabilidade Gerencial da organização investigada.

\subsection{APLICAÇÃO DO CONSTRUTO DE MUDANÇAS NO CAMPO INSTITUCIONAL DE UMA ORGANIZAÇÃO}

Herbert e Seal (2012) aplicaram o construto de Burns e Scapens (2000) para analisar as implicações da implantação de um CSC nas funções da Contabilidade Gerencial de uma organização, conforme descrito no artigo intitulado Shared services as a new organisational form: some implications for management accounting. Este estudo é aqui detalhado em função do mesmo consubstanciar a presente investigação. Os autores analisaram criticamente as afirmações da literatura profissional e de consultores, que propõem que os CSC podem reduzir custos e melhorar a qualidade do serviço de suporte, com o benefício adicional que, tanto o controle como o conhecimento, permanecem na empresa.

Um estudo de caso longitudinal foi realizado pela lente da Teoria Institucional, baseando-se nos modelos de mudança organizacional e de gestão, de Burns e Scapens (2000) e Dillard, Rigsby e Goodman (2004). O objetivo foi compreender o significado de CSC e seu papel no desenvolvimento de processos organizacionais mais amplos, incluindo a Contabilidade Gerencial. Herbert e Seal (2012) buscaram responder as seguintes questões de pesquisa: a) Em que medida o CSC constitui uma nova forma de organização, e não representa uma mudança conceitual na maneira que as sociedades são dirigidas? b) Quais são as implicações dos CSC para a função da Contabilidade Gerencial?

Herbert e Seal (2012) realizaram um estudo de caso em uma grande organização que implantou um CSC, no período de 2003 a 2010. A organização, estabelecida no Reino Unido, é subsidiária de uma concessionária europeia de energia, que fora privatizada nos anos 90 . Entrevistas envolvendo contadores gerenciais, tanto no CSC quanto nas unidades de negócio, duraram cerca de 60 a 90 minutos e foram realizadas por dois entrevistadores. As sessões foram gravadas e, após digitadas por um profissional, uma cópia enviada para cada 
participante a fim de verificar se as respostas estavam registradas conforme seus relatos. Além disso, provas documentais, como relatórios mensais de desempenho, foram analisadas. $\mathrm{O}$ estudo de caso apresentou um detalhado relato evolutivo da criação e implantação do CSC.

Uma nova forma de organização foi constatada, que se mostrou distinta do modelo de terceirização, e diferente dos projetos tradicionais de centralização, tanto conceitualmente quanto operacionalmente, porque adotou práticas híbridas, que combinam a orientação para o mercado com controle hierárquico em curso. A hibridação de práticas e de conhecimentos com a adoção do modelo de CSC foi observada na mudança da Contabilidade Gerencial. Como o processamento de transação foi transferido para o CSC, os contadores gerenciais das unidades de negócios puderam se concentrar em fornecer suporte à tomada de decisão, o denominado conceito de parceria de negócios. Além disso, os contadores gerenciais tiveram a oportunidade de desempenhar novos papéis, como design de sistemas e gestão de processos.

O estudo de Herbert e Seal (2012) contribuiu para o discurso sobre os papéis em desenvolvimento da Contabilidade Gerencial, sob o argumento de que o modelo de CSC gerou novas regras e rotinas em toda a corporação, que tiveram implicações diretas e indiretas nos papéis gerenciais. O modelo de serviços compartilhados apresentou implicações significativas no desenho organizacional e na natureza das funções profissionais, como na Contabilidade Gerencial. O campo do CSC ainda é relativamente novo e seu desenvolvimento abrange uma variedade de formas organizacionais e padrões de implementação.

O modelo do CSC causou mudanças para três grandes dimensões da Contabilidade Gerencial: a) para os papéis dos contadores gerenciais lotados em departamentos; b) para os papéis dos contadores gerenciais transferidos ao CSC; e, c) criação de uma nova relação entre os dois grupos, em que um se torna comprador e o outro fornecedor de serviços de contabilidade. A implantação do CSC na organização apresentou implicações no modelo em termos de ameaças e oportunidades. Houve uma pressão sobre os contadores gerenciais dos CSC para justificar a sua existência como prestadores de serviços para clientes internos; e no processamento de transações de contabilidade pelo CSC, os contadores gerenciais de divisões estavam sob pressão para justificar-se como parceiros de negócios.

Considerando a natureza emergente da literatura acadêmica sobre o tema investigado, os autores recomendam novas pesquisas. Inclusive no tocante ao levantamento dos pontos de vista dos clientes internos do modelo de CSC, a noção de confiança em um arranjo híbrido em relação à terceirização, e também as implicações deste novo modelo em termos de ameaças e oportunidades para contadores e suas organizações profissionais. Neste sentido, para melhor compreender a dimensão de um CSC e as implicações das suas mudanças na estrutura 
organizacional e seu ambiente, na sequência faz-se uma breve caracterização do mesmo.

\subsection{CENTRO DE SERVIÇOS COMPARTILHADOS}

Embora o Centro de Serviços Compartilhados ou Shared Services Center (CSC) não tenha sua origem identificada na literatura em relação ao seu criador, sabe-se que o conceito de serviços compartilhados nas organizações surgiu na década de 80, quando grandes empresas americanas centralizaram seus serviços de backoffice (RAMOS, 2005). O autor aduz que, em 1990, as empresas já utilizavam o conceito e o modelo de CSC. Esta forma de organização, também denominada de shared service, é um mecanismo de racionalização da estrutura organizacional (QUINN; COOKE; KRIS, 2000).

Centro de Serviços Compartilhados (CSC) pode ser definido como a centralização das funções de negócios em uma única unidade de negócio, eliminando uma série de funções de apoio duplicadas (QUINN; COOKE; KRIS, 2000; BERGERON, 2003). Segundo Schulman, Harmer e Dunleavy (1999) e Schuz e Brener (2010), CSC é um conceito organizacional que consolida processos de uma organização para reduzir redundâncias, entregar processos de suporte, ter custos reduzidos e focar no cliente interno. Pereira (2004) acrescenta o aumento do nível de qualidade e possibilidade de crescimento e mudança na organização.

O CSC busca estabelecer uma relação fornecedor/cliente com as unidades de negócio e utiliza índices de desempenho quantificados para influenciar o comportamento e mensurar os resultados (LOZINSKY, 2006). Os benefícios financeiros dos serviços compartilhados, ligados às unidades de negócio da empresa, são alcançados com o aprimoramento dos processos, aumento da eficiência, ganho de escala, diminuição da necessidade de pessoal, arbitragem salarial e reestruturação da pirâmide (QUINN; COOKE; KRIS, 2000; BERGERON, 2003). A implantação dos CSC tem o intuito de aumentar a eficiência operacional com redução dos custos (LOZINSKY, 2006).

De acordo com Gianesi e Corrêa (1994) e Ramos (2005), o CSC simplifica as estruturas organizacionais das unidades de negócio. Os gestores dessas unidades deixam de gerenciar atividades de apoio, como suprimento de materiais, tecnologia da informação, recursos humanos e finanças. Assim, eles podem concentrar-se nas atividades primárias (core business), as quais agregam valor ao produto. Desse modo, o CSC atua como uma unidade organizacional que dispõe de serviços administrativos para as demais subsidiárias ou divisões em um grupo empresarial, eliminando a duplicidade de áreas funcionais na organização (MARTINS; AMARAL, 2008). 
Conforme Quinn, Cooke e Kris (2000), Joia e Mattos (2008), existem quatro modelos de gestão e operação de CSC: Modelo Básico; MarketPlace; MarketPlace Avançado; e Empresa Independente. Para esses autores, as organizações iniciam o processo de implantação do CSC com o modelo básico, que tem como finalidade principal a economia de escala, a qual padroniza os serviços e reduz os custos, garantindo a qualidade dos serviços prestados. A partir da evolução do modelo básico, a gestão do CSC torna-se mais madura, buscando o máximo de qualidade e melhorias efetivas e assim parte para modelos mais avançados (QUINN; COOKE; KRIS, 2000; RAMOS, 2005; JOIA; MATTOS, 2008).

Joia e Mattos (2008) explicam que no modelo MarketPlace a gestão dos serviços torna-se mais autônoma. Existe uma estrutura de governança, que se preocupa em controlar e melhorar as operações, com a definição dos Acordos de Níveis de Serviço (ANS). Já o modelo MarketPlace Avançado só operacionaliza serviços em que o CSC se considera competitivo, os demais são terceirizados, aumentando assim a qualidade dos serviços prestados. O modelo de Empresa Independente organiza o CSC como uma unidade de negócios independente, prestando serviços a diversos clientes, gerando lucro para a organização (JOIA; MATTOS, 2008).

Independente do modelo de gestão e operação de CSC, a decisão de utilização do CSC precisa ser cuidadosamente analisada, dadas as características peculiares e inerentes a cada forma de realização dos serviços. Deve-se considerar não somente os objetivos esperados do modelo e a estratégia da organização, mas também os impactos decorrentes da forma escolhida, a qual acarretará em diferenciadas consequências para a gestão, resultados e efetiva capacidade de atendimento às necessidades das áreas clientes e da organização como um todo a longo prazo (AFFONSO; MARTINS; GONÇALVES, 2012).

De acordo com Martins e Amaral (2008), implantar e manter um CSC em operação envolve desafios complexos, que incluem a formação de uma cultura efetivamente orientada para o usuário dos serviços, a automatização de práticas manuais, a mensuração permanente dos benefícios, o monitoramento das tarefas e alterações no modo de atuar das pessoas na organização. Portanto, com a implantação de um CSC na empresa, transformações ocorrem na sua estrutura organizacional, cujo processo se busca analisar sob a lente da Teoria Institucional, em consonância com o construto proposto por Burns e Scapens (2000).

\section{MÉTODO DA PESQUISA}

Esta pesquisa, com conotação descritiva e abordagem qualitativa do problema, foi 
realizada por meio de um estudo de caso. Este estudo baseou-se na pesquisa de Herbert e Seal (2012), que realizaram um estudo de caso em uma grande organização que implantou um CSC, estabelecida no Reino Unido.

Assim, com base no referencial teórico, particularmente nos estudos de Burns e Scapens (2000) e de Herbert e Seal (2012), estabeleceram-se as categorias e subcategorias de análise, expostas no Quadro 1.

Quadro 1 - Construto utilizado na pesquisa

\begin{tabular}{|l|l|l|}
\hline \multicolumn{1}{|c|}{ Categorias } & \multicolumn{1}{|c|}{ Subcategorias } & \multicolumn{1}{|c|}{ Referências } \\
\hline $\begin{array}{l}\text { Estratégias para } \\
\text { implantação do CSC }\end{array}$ & $\begin{array}{l}\text { Benefícios com implantação do CSC } \\
\text { Evolução das informações contábeis com a } \\
\text { implantação do CSC }\end{array}$ & Herbert e Seal (2012) \\
\hline \multirow{3}{*}{ Estrutura do CSC } & $\begin{array}{l}\text { Funções do contador gerencial } \\
\text { a) Funções anteriores ao CSC } \\
\text { b) Funções com a implantação do CSC }\end{array}$ & Herbert e Seal (2012) \\
& $\begin{array}{l}\text { Regras e Rotinas: } \\
\text { a) Regras e rotinas anteriores ao CSC }\end{array}$ & \\
& $\begin{array}{l}\text { b) Regras e rotinas com a implantação do CSC }(2000) \\
\text { Institucionalização }\end{array}$ & \multirow{2}{*}{ Burns e Scapens (2000) } \\
& $\begin{array}{l}\text { a) Formal versus Infomal } \\
\text { b) Revolucionária versus Evolucionária }\end{array}$ & \\
\hline
\end{tabular}

Fonte: elaborado pelas autoras.

$\mathrm{O}$ instrumento de pesquisa consistiu de um roteiro de entrevista estruturado, com questões para levantar como ocorreu o processo de implantação do CSC na organização, investigar as alterações na estrutura relativas as funções do contador gerencial e analisar o processo de institucionalização das regras e rotinas e o enquadramento das dicotomias conforme definido por Burns e Scapens (2000).

Para a validação do instrumento de pesquisa foram aplicadas as etapas do protocolo definido por Yin (2001). O protocolo contém os procedimentos e as regras gerais a serem seguidas ao utilizar o instrumento, tais como: informação sumária sobre o referencial teórico que sustenta o estudo e documento que possa informar aos entrevistados quais são os objetivos da pesquisa, e suas questões orientadoras iniciais (YIN, 2001).

Desta forma, realizou-se o estudo de caso sobre a implantação de um CSC, cuja estrutura pertence a um grupo empresarial que atua no setor de logística, localizada na região Sul do Brasil. A empresa foi selecionada de forma intencional, pela acessibilidade para desenvolver o estudo. Também devido ao fato de estar vinculada a um cenário requisitado por este estudo, ou seja, implantou um CSC na organização.

O levantamento dos dados necessários para o estudo de caso foi realizado por meio de um roteiro de entrevista semiestruturado, aplicado a dois gestores diretamente envolvidos no 
processo de implantação do CSC, nas funções de Coordenação de Melhoria Contínua e de Coordenação de Contabilidade, respectivamente nos meses de junho e novembro de 2014. As entrevistas tiveram duração média de 52 minutos. A implantação do CSC implicou mudanças no quadro de pessoal, assim os gestores alvo das entrevistas foram os que acompanharam este processo completo na empresa.

Além da entrevista semiestruturada, dados documentais coletados na empresa e em sites foram utilizados na análise, viabilizando a triangulação dos dados. Para Souza (2006), a triangulação é caracterizada pelo exame comparativo de análises de construtos e eventos a partir dos dados oriundos de diversas fontes, o que proporciona maior confiabilidade nos dados disponibilizados para o desenvolvimento da pesquisa. Para Yin (2001), o resultado do estudo de caso é mais convincente e acurado se baseado em distintas fontes de informação.

Para análise dos dados colhidos nas entrevistas, utilizou-se a técnica da análise de conteúdo. Segundo Bardin (2004), a análise de conteúdo é realizada a partir de um conjunto de técnicas de análise das comunicações visando obter, por procedimentos sistemáticos e objetivos de descrição do conteúdo das mensagens, indicadores (quantitativos ou não) que permitam a inferência de conhecimentos relativos às condições de produção/recepção (variáveis inferidas) destas mensagens.

Diante das etapas da técnica de análise, conforme Bardin (2004), a pesquisa foi organizada em três fases: (a) pré-análise, organizada em quatro etapas - (i) leitura flutuante, que é o estabelecimento de contato com os documentos da coleta de dados; (ii) escolha dos documentos a serem analisados, (iii) formulação das hipóteses e objetivos, e (iv) referenciação dos índices e elaboração de indicadores; (b) exploração do material codificação, classificação e categorização dos dados coletados; e, (c) tratamento dos resultados, inferência e interpretação. Essas fases foram desenvolvidas manualmente já que o volume de dados colhidos nas entrevistas não era elevado e para evitar a possibilidade de perda de informações relevantes para o desenvolvimento do estudo.

Para analisar a institucionalização de regras e rotinas da Contabilidade Gerencial com a implantação do CSC, foram consideradas as quatro etapas propostas por Burns e Scapens (2000), que se constituem do processo de codificação, incorporação, reprodução e institucionalização. No entanto, o modelo proposto pelos autores não demonstra a forma de compor as etapas que constituem os campos de ação e de institucionalização no processo institucional. Guerreiro e Pereira (2005) destacam que a Teoria Institucional, mesmo contendo uma estrutura conceitual adequada para o entendimento da institucionalização, não propõe uma forma operacional de avaliação do processo institucional. 
Desta forma, foi necessário estabelecer um conjunto de categorias de análise apra conduzir as entrevistas na empresa e analisar, posteriormente, seu conteúdo. Essas categorias compõem os campos de ação e de institucionalização no processo institucional. Neste sentido analisaram-se de modo preliminar os relatórios da administração da empresa dos anos de 2006 a 2010, visto que são anteriores e posteriores ao período de implantação de CSC, no intuito de identificar mudanças estruturais que pudessem ter motivado alterações nos hábitos e rotinas da organização.

\section{DESCRIÇÃO E ANÁLISE DOS RESULTADOS}

A descrição e análise dos resultados inicia com uma breve caracterização da empresa objeto de estudo. Em seguida discorre sobre as estratégias de implantação do CSC adotadas pela empresa e a sua estrutura. Na sequência aborda sobre o processo de institucionalização das normas e rotinas do CSC e as dicotomias de mudanças advindas da implementação destes serviços compartilhados na empresa. Por último, destaca as implicações do CSC nas funções da Contabilidade Gerencial da empresa objeto de estudo.

\subsection{DESCRIÇÃO DA EMPRESA OBJETO DO ESTUDO DE CASO}

O estudo de caso foi realizado em uma empresa independente de logística, da América Latina. Fundada em 1997, com a concessão da Rede Ferroviária Federal (RFFSA) para atuar na malha sul do país, essa companhia vem ampliando sua atuação em um histórico de aquisições no setor de logística brasileiro. Atualmente, atua com uma variedade de serviços por meio de quatro concessões ferroviárias no Brasil, totalizando 12,9 mil km de ferrovias: sendo uma de operações ferroviárias, uma subsidiária que presta serviços de logística intermodal de contêineres, uma empresa voltada para o negócio rodoviário, e uma empresa que apresenta solução logística mina-ferrovia-porto para o minério de ferro entre as cidades brasileiras de Corumbá e Santos.

Com o objetivo de se tornar a melhor empresa de logística da América Latina, declara como valores: foco no cliente; integridade e transparência; simplicidade com criatividade e austeridade; metodologia e qualidade para melhorar sempre; trabalho em equipe com alegria e segurança; responsabilidade com a comunidade e o meio ambiente. A empresa mantém um sistema de gestão para sustentar os resultados da companhia por meio do modelo de excelência em gestão da qualidade. 
Em 2008, à luz de uma nova oportunidade de negócio, visando redução de custos e otimização de processos, a companhia implantou um Centro de Serviços Compartilhados, uma unidade separada da empresa, que centralizou atividades, tais como: contabilidade, recursos humanos, pagamentos, recebimentos, cobranças, conciliações financeiras, arquivos e outras atividades operacionais que não fazem parte da atividade fim da companhia. Esta unidade é foco de análise do presente estudo.

\subsection{ESTRATÉGIAS DE IMPLANTAÇÃO DO CSC}

$\mathrm{Na}$ análise de conteúdo das entrevistas foi possível perceber que grande parcela das vantagens apontadas na implantação do CSC em um grupo empresarial de grande porte é condizente com as vantagens observadas no referencial teórico deste estudo, em especial vantagens como a redução de custos e aumento na qualidade das atividades, conforme citado por Schulman et al. (2001) e confirmado na pesquisa realizada pela Deloitte (2007), mas diferenciando-se dos resultados encontrados no estudo de Robert e Seal (2012).

Os gestores entrevistados da empresa viram o CSC como uma oportunidade de negócio. O propósito no longo prazo é de migrar o CSC para o modelo de Empresa Independente, como uma unidade de negócios independente, que tem como intuito prestar serviços a diversos clientes e gerar lucro para a organização (JOIA; MATTOS, 2008). No entanto, na fase inicial da implantação do CSC, o principal ganho da empresa apontado por um dos entrevistados foi a redução de custos:

[...] houve sim uma grande redução de custos, porque muitas coisas que eram feitas na empresa, como, por exemplo, lançamento e pagamento de notas fiscais, exigiam pelo menos 20 pessoas para executarem essas atividades. Hoje, no CSC, não há 10 pessoas para a mesma função.

Na empresa também foram identificados outros benefícios com a implantação do CSC, em especial, a segurança e o controle. Esses aspectos representam aumento no nível de qualidade dos serviços prestados, conforme Pereira (2004). Isso foi enfatizado na fala de um dos entrevistados: “[...] temos um controle melhor do que a área de origem. Conseguimos fazer isso porque temos a centralização, o que outros setores não teriam, como, por exemplo, o controle do sistema financeiro". 
Um dos entrevistados, ao fazer o comparativo do organograma anterior e o atual, relatou que, para a implantação do CSC, a empresa já possuía um diretor apto a auxiliar nesse processo e convicto de que seria uma excelente oportunidade para a empresa. Desse modo, foi constituída uma equipe para realizar as atividades do CSC com pessoas internas à empresa, sendo os mesmos transferidos para essa nova unidade.

Pela análise de documentos foi observado que a empresa contou com a ajuda de profissionais externos na implantação do CSC. A ajuda veio de uma empresa de consultoria nacional de grande porte, que segundo um dos entrevistados auxiliou na implantação desta unidade centralizada. Para adequar-se ao mercado de serviços compartilhados foi realizado um benchmarking, que a empresa de consultoria utilizava.

De acordo com um dos entrevistados, também teve a participação dos gestores em um grupo de gestão, coordenado por um grupo de engenharia de gestão. Este grupo realizava uma reunião mensal para trocar ideias sobre os procedimentos de centralização. Um dos entrevistados mencionou que ainda hoje é realizado o benchmarking:

[...] é importante essa troca, participar de fóruns e com esse benchmarking é possível trazer novidades relativas a processos e sistemas, inclusive de redução de custos. [...] a empresa (CSC) tem o objetivo de agregar valor aos serviços prestados. Hoje entregamos os relatórios com as devidas análises e temos como objetivo fazer um trabalho diferenciado, agregando valor aos processos.

Foi possível observar o desafio da melhoria contínua presente no CSC estudado. Isso está em linha com os resultados da pesquisa de Portulhak et al. (2013, p. 14), em que a resposta a esse questionamento foi: "a estrutura organizacional e as políticas são fatores vivos e necessitam estarem se reinventando constantemente, acompanhando melhores práticas e tendências de mercado". Os entrevistados da presente pesquisa destacaram que:

Houve melhoria de padronização de processos, prazos, implantação de sistemas [...]. Isso reduziu tempo. Reduziu também os pagamentos não realizados.

[...] aumentou a produtividade e a excelência nos serviços. Hoje estamos trabalhando na qualidade e melhoria dos serviços. [...] mais 
qualidade do que redução de custos.

Os benefícios reportados de aprimoramento dos processos, aumento da eficiência e ganho de escala estão em linha com os apontados nos estudos de Quinn, Cooke e Kris (2000) e Bergeron (2003). No entanto, chama a atenção que, embora a implantação do CSC tenha o propósito de aumentar a eficiência operacional com redução dos custos (LOZINSKY, 2006), o entrevistado destacou que o foco é mais na qualidade do que na redução de custos.

Em uma das notícias veiculadas no portal Fator Brasil (2012), sobre os benefícios dos Centros de Serviços Compartilhados, é mencionado que a empresa pesquisada neste estudo alcançou a excelência em CSC, pois obteve um crescimento de 50\% no CSC e foi premiada na categoria Best New do Congresso IQPC Shared Services do Brasil como o Melhor Centro de Serviços Compartilhados do país, isso com menos de três anos de operação. A notícia da excelência não foi cotejada e pode ser objeto de pesquisas sobre o desempenho de CSC.

O projeto da implantação do CSC iniciou em 2007, com um local que centralizava atividades administrativas, essenciais para o suporte ao negócio. A consultoria especializada na migração de processo de áreas descentralizadas para um CSC, segundo o portal Fator Brasil (2012), foi fator chave para a redefinição de processos, sem os executivos envolvidos precisar parar suas atividades diárias. Ainda que esta notícia tenha que ser analisada com parcimônia, a consultoria acompanhou todo o processo até o CSC entrar em operação.

Outra estratégia apontada no relato dos entrevistados foi a localização do CSC. Uma cidade próxima da empresa teve como fatores determinantes a qualidade e disponibilidade de mão de obra a um custo competitivo, o que coaduna com a tendência observada no estudo da Deloitte (2007). A escolha da região para a instalação do CSC também se deu em função de já possuir ali a estrutura administrativa da empresa, o que segue uma tendência citada pela Bain \& Company (2004), de optar por cidades fora dos principais centros urbanos do país.

\subsection{ESTRUTURA DO CSC}

O CSC objeto de estudo configura como uma unidade separada da empresa e possui controle direto e indireto sobre as informações das empresas do grupo. No Relatório da Administração de 2008, consta que a companhia implantou um CSC sob a forma de uma unidade separada, que centralizou atividades que não fazem parte da atividade fim da companhia, como: contabilidade, recursos humanos, pagamentos, recebimentos, cobranças, conciliações financeiras, arquivos e outras atividades operacionais. 
Anteriormente a estrutura da empresa era totalmente descentralizada, assim havia maior quantidade de atividades de suporte operacionais, inclusive rotinas de RH. O CSC transformou-se em um fornecedor desses serviços, sendo esta a principal mudança após a sua implantação, visto que antes existiam departamentos nas unidades de negócio que realizavam essas atividades, hoje a empresa possui uma única unidade que realiza as atividades das áreas.

Ao serem questionados sobre as atividades transferidas das unidades de negócio da empresa para o CSC quando de sua implantação, os entrevistados reportaram que:

[...] o primeiro setor transferido para o CSC foi o RH, menos o recrutamento e seleção, que está no coorporativo. As rotinas do departamento de pessoal e a seleção para o CSC são feitas no CSC. Depois foram transferidas as atividades de faturamento, emissão de notas e pagamento de fornecedores. A contabilidade, demonstrações financeiras e fiscal também são feitas no CSC. Também foi transferido parte do TI (células de resolução de problemas). Além de outros back office, como de suprimentos e contratos, os jurídicos (coorporativos) como agendamentos de audiências, busca de prepostos etc.

[...] Os pagamentos são feitos todos no CSC, inclusive judiciais e trabalhistas. A área financeira, contas a receber, conciliação financeira e cobranças estão no CSC. Back office de tesouraria, de relatórios gerenciais e financeiros, parte dos resultados estão no CSC. Há uma central de atendimento no CSC, no coorporativo tem uma ouvidoria, mas atendimento aos funcionários, fornecedores e clientes estão no CSC. A expedição e recepção de documentos também. Os arquivos são terceirizados, mas o controle é feito no CSC. Áreas de controles operacionais e atividades que não são da atividade fim da empresa, de modo geral, vieram para o CSC.

Embora algumas pessoas tenham sido transferidas da empresa para o CSC, diversos foram contratados do mercado, assim como aconteceu no estudo de Robert e Seal (2012). Após a implantação do CSC, foi percebido que alguns relatórios não eram utilizados, assim, os setores criados para produzi-los foram extintos e os empregados demitidos. Isso coaduna 
com os argumentos de Quinn, Cooke e Kris (2000) e Bergeron (2003) quanto aos benefícios financeiros dos serviços compartilhados, decorrentes do aprimoramento dos processos e diminuição da necessidade de pessoal, arbitragem salarial e reestruturação da pirâmide.

Com base em relatos dos entrevistados e triangulação de informações baseadas em documentos internos e externos, foi possível fazer o design da estrutura do CSC, conforme demonstrado na Figura 2.

Figura 2 - Estrutura do CSC

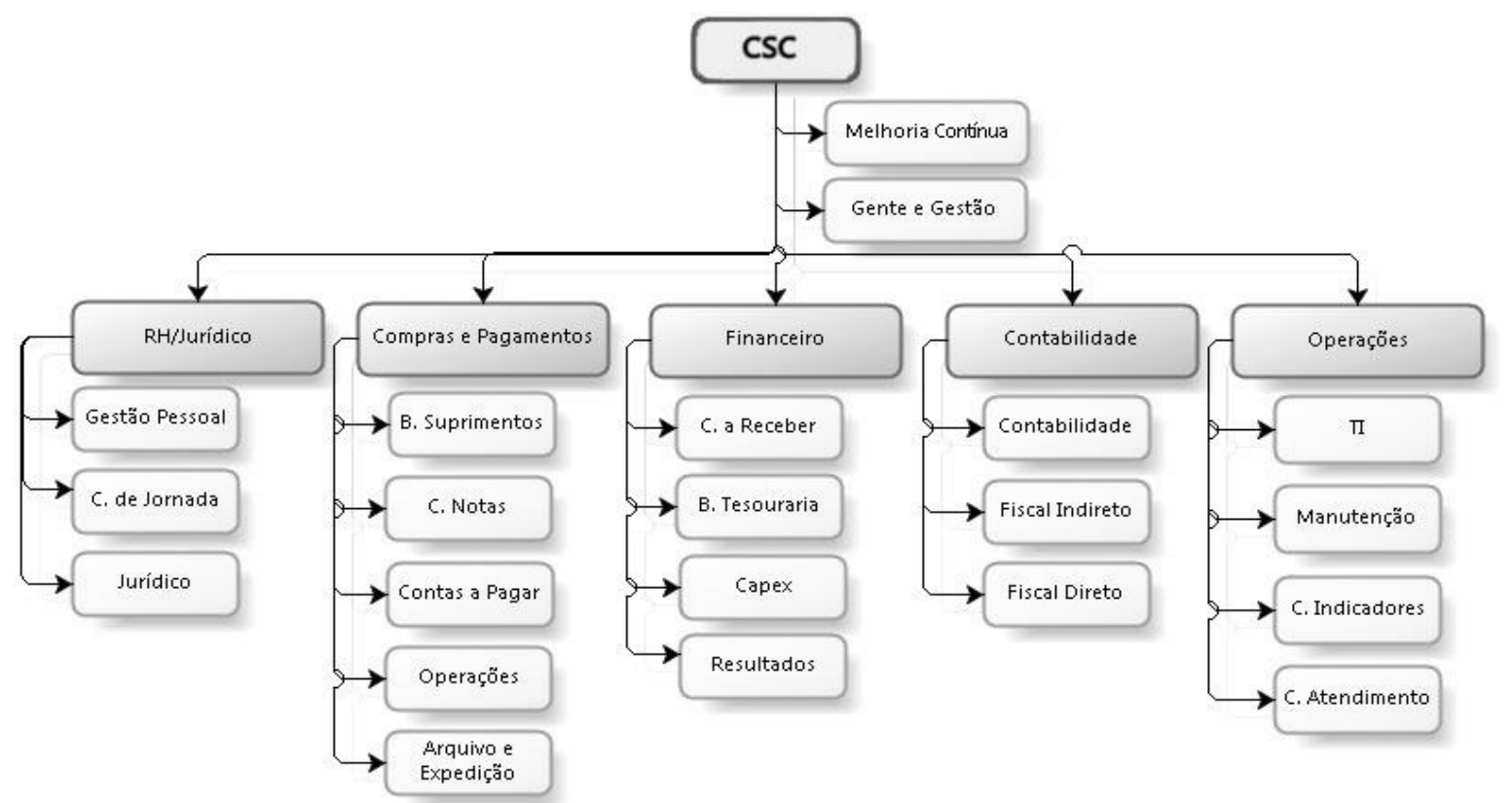

Fonte: elaborada pelas autoras com base nos relatos dos entrevistados e documentos do CSC.

Um aspecto destacado nas entrevistas está em linha com o observado por Kearney (2004), que diz respeito a presença da resistência às mudanças por parte dos empregados, apontado como uma das dificuldades enfrentadas pela empresa objeto de estudo quando da implantação da estrutura de serviços compartilhados. Segundo um dos entrevistados: "Teve resistência na implantação do CSC. Há um mito que as pessoas vão ser esquecidas quando transferidas para o CSC. Alguns acreditavam que não iria dar certo, outros achavam que a empresa iria perder o controle, como o de pagamentos".

Em atas de reuniões realizadas no período de implantação do CSC pelo grupo de gestão, coordenado por um grupo de engenharia de gestão, observa-se que a preocupação com a resistência de pessoas e possíveis ações para mitiga-la eram recorrentes. Ressalta-se, conforme o relato de um dos entrevistados, que a empresa realizou treinamentos com os empregados para adaptação no período de implantação do CSC: “[...] muitos processos foram perdidos, hoje temos o controle. É feito um mapeamento de atividades e treinamento com a 
auditoria. Os treinamentos são constantes devido às mudanças ocorridas".

Se, de um lado, inicialmente parecia resistência de pessoas, de outro lado denota-se que o temor de alguns funcionários se materializou com a perda de processos durante a implantação do CSC. No entanto, mediante treinamentos, criação de controles e realização de auditorias, essas dificuldades foram supridas e contornadas ao longo do tempo.

\subsection{PROCESSO DE INSTITUCIONALIZAÇÃO}

O processo de institucionalização do CSC é analisado, na sequência, em duas perspectivas: (i) regras e rotinas; e (ii) dicotomias de mudança.

\subsubsection{Regras e Rotinas}

A implantação do CSC promoveu mudanças significativas na estrutura operacional da empresa. Para categorizar os diferentes tipos e graus de mudança e a institucionalização de regras e rotinas utilizou-se o quadro de Burns e Scapens (2000), a exemplo do procedimento adotado no estudo de Herbert e Seal (2012), que se compõe das fases de codificação, incorporação e reprodução, para então atingir a institucionalização.

Conforme o relato de um dos entrevistados, a implantação do CSC ocorreu por decisão da diretoria da empresa, especificamente por um diretor (que não faz mais parte do quadro de pessoal da empresa) que assimilou a ideia e formou uma equipe, com pessoal interno, para operacionalizar o CSC. Na Figura 3 apresenta-se o processo de institucionalização das regras e rotinas do CSC na empresa.

Figura 3 - Institucionalização das regras e rotinas no CSC

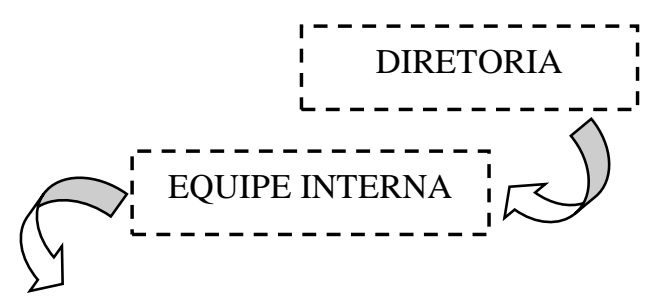




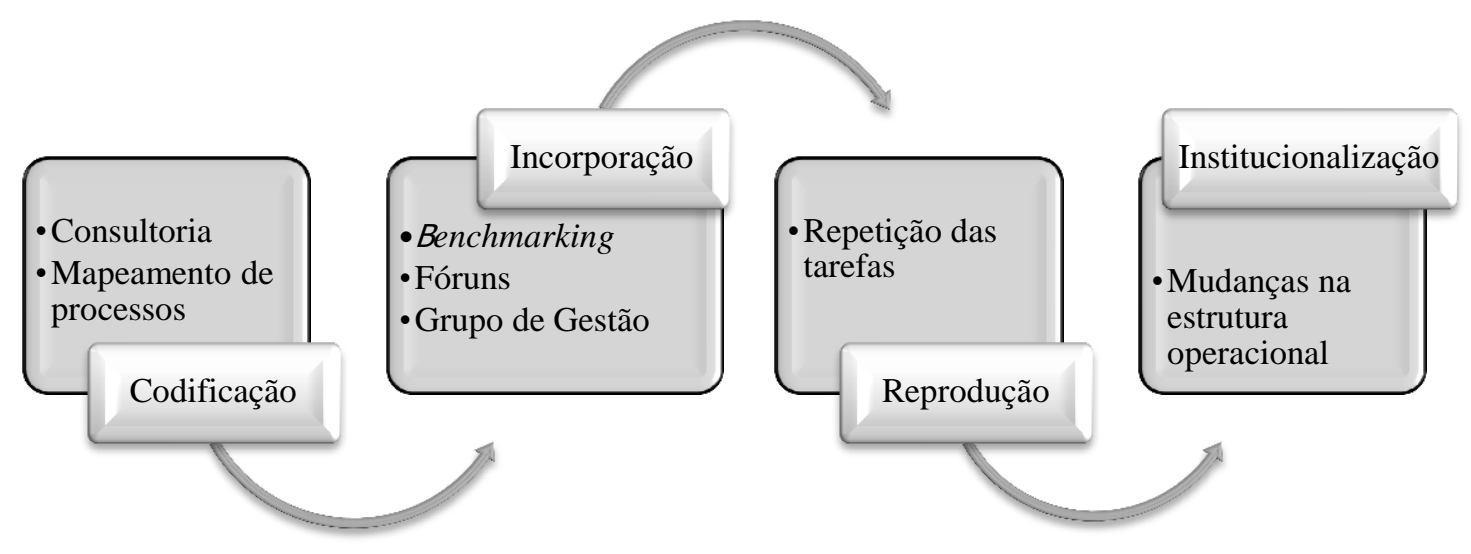

Fonte: elaborado pelas autoras com base nos relatos dos entrevistados e documentos do CSC.

A codificação dos princípios institucionais (significados, valores e poderes existentes) em regras e rotinas, conforme preconizado por Burns e Scapens (2000), foi realizada por uma empresa de consultoria, que fez o mapeamento dos processos antes e após a implantação: "[...] Havia um diretor que comprou a ideia, ele foi montando o time do CSC (pessoas internas). Hoje um superintendente responde para a diretoria da empresa, que estava no grupo de transição. Ele teve ajuda de consultoria para o processo de implantação".

Assim como evidenciado por Guerreiro et al. (2008), é necessário um constante monitoramento das variáveis ambientais e da sua influência nos sistemas da empresa. Para a incorporação das regras e rotinas, conforme um dos entrevistados, a empresa realiza continuamente o monitoramento de seus processos, por meio de benchmarking, participação de fóruns e um grupo de gestão denominado de Compartilha. As reuniões são realizadas mensalmente no CSC para verificar se os processos estão sendo realizados com qualidade e com redução de custos.

[...] Foi feito um benchmarking, que a empresa de consultoria possuía. Existe um grupo que chama-se Compartilha, é um grupo de coordenação de engenharia de gestão. É feita uma reunião mensal para trocar ideias, e ainda hoje é realizado um benchmarking. É importante essa troca e participar de fóruns, para trazer novidades com relação a processos e sistemas, inclusive com relação a redução de custos. 
Em consonância com o observado no estudo de Herbert e Seal (2012), o CSC objeto de análise gerou novas regras e rotinas em toda a corporação, que tiveram implicações diretas nas funções e departamentos da empresa, resultando na hibridação de práticas e conhecimentos. Com a implantação do CSC, as atividades operacionais que antes eram realizadas por várias pessoas de setores diferentes da empresa, atualmente são realizadas pelas mesmas pessoas ou pelo mesmo setor, o que facilita a reprodução de rotinas pela repetição das tarefas, fato importante para sua institucionalização. De acordo com um dos entrevistados, a repetição do comportamento ocorre: "[...] conforme são desenvolvidos os procedimentos operacionais (POs). Com isso a rotina se torna clara e de fácil entendimento".

Assim como constatado na pesquisa realizada por Guerreiro et al. (2008) em uma organização brasileira, o processo de institucionalização desses novos hábitos e rotinas foi pautado por estratégias, como o uso de sistemas, visando à automação das tarefas e eliminação de antigos procedimentos manuais e pessoais, e a realização de treinamento para propiciar capacitação no emprego dos novos conceitos, além de monitoramento constante das atividades. A institucionalização das regras e rotinas permite verificar as mudanças ocorridas nas unidades. Um dos entrevistados reportou que: “O CSC transformou-se em um fornecedor, antes tinha departamentos que realizavam várias atividades, hoje temos uma unidade centralizando as atividades".

Denota-se que as fases de codificação, incorporação, reprodução e institucionalização do construto de Burns e Scapens (2000) foram essenciais para o processo de mudanças na empresa objeto de estudo, por proporcionar a substituição de velhas práticas por novos conceitos, hábitos e rotinas. Tal também foi observado por Guerreiro et al. (2008), ao investigarem a institucionalização de mudanças implementadas na Contabilidade Gerencial da maior instituição financeira do Brasil, e por Herbert e Seal (2012), que analisaram a institucionalização da mudança organizacional e de gestão com a implantação de um CSC e suas implicações nas funções da Contabilidade Gerencial em uma grande organização estabelecida no Reino Unido.

\subsubsection{Dicotomias de mudanças}

A implantação do CSC na empresa em análise implicou em uma nova configuração no organograma, tão logo que o pessoal de apoio e suas atividades associadas foram transferidos para o CSC. No entanto, não ocorreram apenas mudanças estruturais, mas principalmente de regras e rotinas na prestação desses serviços, inclusive com implicações nas funções da Contabilidade Gerencial. Com base no modelo proposto por Burns e Scapens (2000), foi 
realizada a análise das dicotomias de mudanças, conforme demonstrado na Figura 4.

Figura 4 - Dicotomias de mudanças com a implantação do CSC

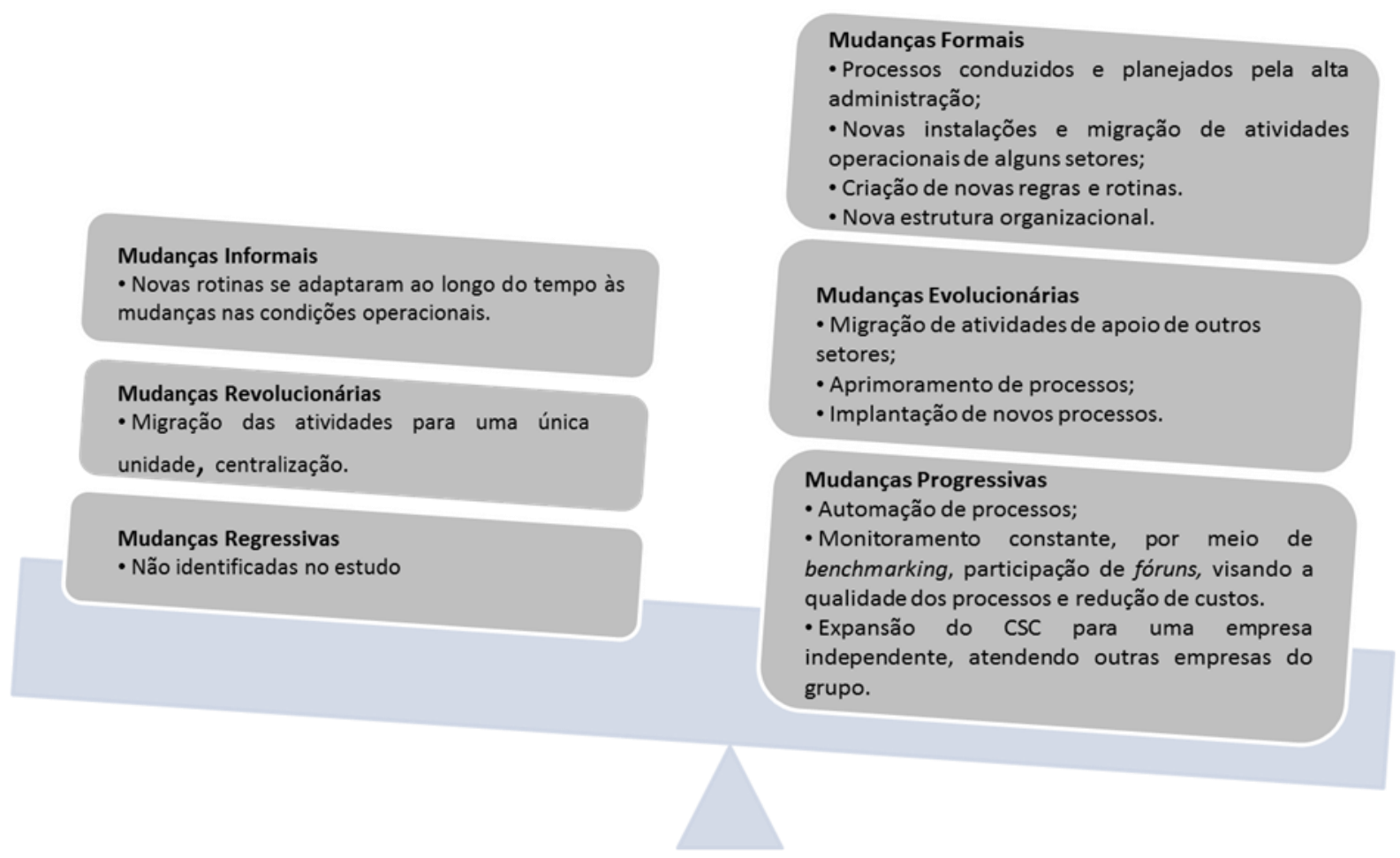

Fonte: elaborado pelas autoras com base nos relatos dos entrevistados e documentos do CSC.

Na Figura 4 há uma balança simbólica das dicotomias de mudanças observadas na implantação do CSC. Nota-se que as mudanças ocorridas na empresa, assim como no estudo de Herbert e Seal (2012), foram mais formais do que informais, na medida em que o processo se iniciou pela alta administração, implicou nova estrutura organizacional, com novas instalações e migração física de atividades de apoio, conforme já comentado anteriormente. Um dos entrevistados reportou que: “As mudanças foram bem mais formais, passando por vários processos. No início houve muitas coisas informais, que depois foram tornando-se formais".

Esse relato coaduna com o preconizado por Quinn, Cooke e Kris (2000), Joia e Mattos (2008), que o processo de implantação do CSC em uma organização, no início, tem como finalidade principal a economia de escala, a qual implica na padronização dos serviços e, assim, reduz os custos e garante a qualidade dos serviços prestados. A evolução desse modelo básico torna a gestão do CSC mais madura e permite que adote modelos mais avançados.

Em relação à segunda dicotomia, a mudança revolucionária envolve uma interrupção substancial nas regras e instituições existentes, enquanto que a mudança evolucionária é 
incremental, com uma interrupção menor nas rotinas e instituições existentes (BURNS; SCAPENS, 2000). Consoante ao estudo de Herbert e Seal (2012), para um dos entrevistados: "[...] apesar da mudança de instalações, as mudanças foram bem mais evolutivas, ocorrendo a migração de novos processos, bem como o seu aprimoramento".

As mudanças foram progressivas, com a migração física, reengenharia e integração dos processos. Conforme o quadro de referência de Burns e Scapens (2000), a implantação do CSC acarretou em uma mudança institucional, com a criação de suas próprias regras e rotinas: "[...] foram criadas as nossas próprias regras e rotinas, segue-se uma linha diferente".

Assim como no estudo de Herbert e Seal (2012), novas regras foram definidas nos Acordos de Nível de Serviço (Service Level Agreements - SLA) e com novos indicadores de desempenho (Key Performance Indicators - KPI) alinhados entre as partes. No atendimento ao cliente, foram criadas novas rotinas operacionais, resultando em reengenharia e padronização de processos. Em relação à cobrança, foi desenvolvido um programa que busca dados do cliente direto da nota fiscal, evitando os erros que ocorriam quando os dados eram digitados manualmente. Também ocorreu melhoria significativa no controle das atividades: "Temos um melhor controle do que a área de origem. Conseguimos fazer isso porque temos a centralização que os outros setores não tinham".

Portanto, a implantação do CSC permitiu uma maior visibilidade e responsabilidade para os serviços de apoio, provocando mudanças organizacionais significativas, que se refletiram em todos os ambientes da empresa, inclusive nas funções da Contabilidade Gerencial. Isso reforça as dicotomias de mudanças do modelo de Burns e Scapens (2000) observadas no CSC, em que se destacaram as formais, evolucionárias e progressivas.

\subsection{Implicações do CSC nas funções da Contabilidade Gerencial}

A implantação do CSC, assim como observado no estudo de Herbert e Seal (2012), provocou mudanças em três dimensões da Contabilidade Gerencial: (i) nos papéis dos contadores gerenciais que ficaram nas unidades de negócio; (ii) nos papéis dos contadores gerenciais que foram para o CSC; e (iii) na criação de uma nova relação entre esses dois grupos, pois os contadores gerenciais das unidades de negócio passaram a ser usuários dos serviços dos contadores gerenciais do CSC. Segundo um dos entrevistados, antes da implantação do CSC: “[...] a estrutura contábil das unidades de negócios contava com duas gerências, uma contábil e outra fiscal. O contador gerencial era responsável por toda a parte da auditoria e de relatórios que davam suporte à diretoria da empresa". 
Com a implantação do CSC houve uma reestruturação, alguns funcionários da contabilidade ficaram no coorporativo e outros foram para o CSC, além da necessidade de novas contratações. Ao contador do CSC coube gerenciar todos os processos da área contábil e fiscal, por exemplo, a elaboração das demonstrações financeiras e entrega de obrigações acessórias, confirmando assim o papel dos CSC de controlar e melhorar esses processos da empresa. Como resultado dessa mudança, foi apontado por um dos entrevistados que houve: "[...] melhoria no processo de geração da informação contábil, com redução de $50 \%$ do tempo de entrega, e preocupação de entregar ao cliente, no caso à controladoria, o que realmente ele precisa".

Nota-se pelo exposto que o maior impacto ocorreu nas funções dos contadores gerenciais das unidades de negócio. Um dos entrevistados mencionou que eles: “[...] perderam o controle direto sobre o processamento das transações, que ficou com a controladoria. Todos os relatórios contábeis produzidos no CSC são encaminhados à controladoria antes de seguirem para a diretoria, cabendo a esses contadores a análise e a produção de novas informações de suporte à tomada de decisão".

Guerreiro et al. (2008, p. 83) aduzem que "o sucesso da implantação de um novo modelo gerencial está diretamente associado à capacidade da empresa de trocar velhos hábitos por novos hábitos". Na medida em que os contadores das unidades de negócio viram-se livres das atividades de processamento das transações, tiveram a oportunidade e ao mesmo tempo o desafio de reforçar o papel global da função da Contabilidade Gerencial (HERBERT; SEAL, 2012). Essa destaca-se pela capacidade de gerar informação para auxiliar na tomada de decisões (HORNGREN; SUNDEM; STRATTON, 1996).

Aos contadores gerenciais das unidades de negócio coube a institucionalização de novas práticas de apoio à gestão, como o desenvolvimento de indicadores adequados, sistemas de monitoramento e avaliação de desempenho, além da participação pró-ativa no planejamento, tomada de decisão e controle dentro das equipes estratégicas e operacionais (GOSPEL; SATO, 2010).

Como toda a mudança gera resistências das pessoas nas organizações, no setor de Contabilidade Gerencial do CSC da empresa pesquisada não foi diferente. O processo de implantação do CSC acarretou redução do número de funcionários no departamento, gerando insegurança e expectativa de reforçar o papel global da função da Contabilidade Gerencial. Neste caso, até houve redução do número de funcionários, mas principalmente reestruturação do setor conforme mencionado anteriormente. 


\section{CONSIDERAÇÕES FINAIS}

Este estudo objetivou analisar, sob a abordagem institucional, as implicações da implantação de um Centro de Serviços Compartilhados (CSC) nas funções da Contabilidade Gerencial. Diversas afirmações e constatações teórico-empíricas apontadas no referencial teórico obtiveram destaque na compilação e interpretação dos dados obtidos em relação a implantação do CSC na empresa objeto do estudo de caso.

A análise, sob a lente da Teoria Institucional, da criação e desenvolvimento de um modelo de Centro de Serviços Compartilhados em uma empresa proporcionou diversas contribuições teórico-empíricas. Inicialmente, essa forma de organização mostrou-se distinta da terceirização de serviços, visto que a empresa adotou práticas híbridas, que combinam a orientação para o mercado com o controle hierárquico interno em curso, possibilitando melhorias na padronização dos processos.

As dicotomias de mudanças analisadas com base no modelo proposto por Burns e Scapens (2000) indicaram que, na implementação do CSC na empresa, prevaleceram as mudanças formais em detrimento das informais, as evolucionárias e relação as revolucionárias e as progressivas em comparação com as regressivas. Esses resultados devem ser observados com parcimônia, pois são baseados nos relatos dos gestores entrevistados e na análise de documentos da empresa, mas não foram entrevistados os usuários dos serviços.

Em relação às implicações nas funções da Contabilidade Gerencial com a implantação do CSC na empresa, os papéis desenvolvidos pela Contabilidade Gerencial, comparando o período anterior e o pós-implantação do modelo de CSC, seja nas unidades de negócio e/ou no CSC, geraram novas regras e rotinas em toda a corporação. Observaram-se implicações diretas e indiretas nos papéis dos profissionais da Contabilidade Gerencial, como o de reforçar o papel global da função da Contabilidade Gerencial na unidade de negócio e na organização como um todo, corroborando com os resultados de Herbert e Seal (2012).

Conclui-se que na empresa pesquisada, o modelo de CSC teve implicações significativas na estrutura organizacional e na natureza das funções da Contabilidade Gerencial, as quais resultaram na institucionalização de novas regras e rotinas nos moldes preconizados por Burns e Scapens (2000). No entanto, o campo do CSC ainda é relativamente novo, como observado na literatura, dado que pode abranger uma ampla variedade de motivações, formas organizacionais, áreas funcionais e padrões de implementação.

Dada a natureza emergente da literatura acadêmica, mais pesquisas sobre o CSC são necessárias. Portanto, recomenda-se replicar este estudo em outro ramo de atividade, a fim de 
comparar os seus reflexos na Contabilidade Gerencial. Outra sugestão é verificar se o crescimento do CSC se assemelha em outras empresas, visto que a empresa em questão não possui concorrentes, o que pode ter facilitado o desenvolvimento do seu CSC. Além disso, a empresa em questão atende assuntos relativos às empresas parceiras, assim seria interessante comparar com uma empresa que implantou o CSC e que atende somente a unidade principal.

\section{REFERÊNCIAS}

AFFONSO, H. J.; MARTINS, H. C.; GONÇALVES, C. A. Centro de Serviços

Compartilhados em modelo próprio ou terceirizado: um estudo comparativo multicasos. In: SIMPÓSIO DE ADMINISTRAÇÃO DA PRODUÇÃO, LOGÍ12STICA E OPERAÇÕES INTERNACIONAIS, 15., 2012, São Paulo. Anais... São Paulo: FGV/SP, 2012.

BAIN \& COMPANY. Centro de Serviços Compartilhados: uma solução definitiva para os processos administrativos? 2005. Disponível em:

<http://www.bain.com.br/bainweb/PDFs/cms/Public/Centros_de_servicos_compartilhados_P ortuguese.pdf >. Acesso em: 17 maio 2014.

BAINES, A.; LANGFIELD-SMITH, K. Antecedents to management accounting change: a structural equation approach. Accounting, Organizations and Society, v. 28, n. 7/8, p. 675693, 2003.

BARDIN, L. Análise de conteúdo. 3. ed. Lisboa: Edições 70, 2004.

BERDEJO, L. M. A. Fatores de resistência ao processo de implementação de um Centro de Serviços Compartilhados: uma abordagem segundo a teoria institucional. 2009. 184fls. Dissertação (Mestrado em Ciências Contábeis) - Universidade de São Paulo, São Paulo, 2009.

BERGERON, B. Essentials of shared services. 2. ed. New Jersey: John Wiley \& Sons, 2003. BURNS, J. The dynamics of accounting change: inter-play between new practices, routines, institutions, power and politics. Accounting, Auditing and Accountability Journal, v. 13, n. 5, p. 566-586, 2000.

BURNS, J.; SCAPENS, R. Conceptualizing management accounting change: an institutional framework. Management Accounting Research, v. 11, n. 1, p. 3-25, 2000.

CLEGG, S. R.; HARDY, C. Introdução: organização e estudos organizacionais. In: CLEGG, S. R.; HARDY, C.; NORD, W. R. (orgs.). Handbook de estudos organizacionais: modelos de análise e novas questões em estudos organizacionais. 3. ed. São Paulo: Atlas, 2006. Vol. 2. p 437-460. 
DILLARD, J.; RIGSBY, J.; GOODMAN, C. The making and remaking of organization context: duality and the institutionalization process. Accounting, Auditing \& Accountability Journal, v. 17, n. 4, p. 506-542, 2004.

FACHIN, R.; MENDONÇA, R. O conceito de profissionalização e da teoria institucional. In: VIEIRA, M. F.; CARVALHO, C. A. (Orgs.). Organizações, instituições e poder no Brasil. Rio de Janeiro: FGV, 2003. p. 19-41.

FATOR BRASIL. Os benefícios dos Centros de Serviços Compartilhados. Revista Fator Brasil, 2012. Disponível em:

<http://www.revistafatorbrasil.com.br/ver_noticia.php?not=192783>. Acesso em: 20 nov 2014.

GIANESI, I.; CORREA, H. Administração estratégica de serviços. São Paulo: Atlas, 1994. GOSPEL, H.; SAKO, M. The unbundling of corporate functions: the evolution of shared services and outsourcing. Industrial and Corporate Change, v. 19, n. 5, p. 1367-1396, 2010.

GUERREIRO, R.; FREZATTI, F.; CASADO, T. Em busca de um melhor entendimento da contabilidade gerencial através da integração de conceitos da psicologia, cultura organizacional e teoria institucional. Revista Contabilidade \& Finanças, v. 17, n. spe., p. 721, 2006.

GUERREIRO, R.; PEREIRA, C. A. A avaliação do processo de mudança da contabilidade gerencial sob enfoque da teoria institucional: o caso do Banco do Brasil. In. EnANPAD, 29,. Brasília, 2005. Anais... Rio de Janeiro: ANPAD, 2005.

GUERREIRO, R.; PEREIRA, C. A.; FREZATTI, F. Aplicação do modelo de Burns e Scapens para avaliação do processo de institucionalização da contabilidade gerencial. Organizações \& Sociedade, v. 15, n. 44, p. 45-62, 2008.

HERBERT, I.; SEAL, W. Shared services as a new organizational form: some implications for management accounting. The British Accounting Review, v. 44, n. 2, p. 83-97, 2012. HOPPER, T.; MAJOR, M. Extending institutional analysis through theoretical triangulation: Regulation and activity based costing in Portuguese Telecommunications. European Accounting Review, v. 16, n. 1, p. 59-97, 2007.

JOIA, E.; MATTOS, M. Conceitos e definições de um centro de serviços compartilhados. 2008. Trabalho de Conclusão de Curso (Monografia) - Escola Politécnica da UFRJ, Rio de Janeiro, RJ, Brasil, 2008.

LOZINSKY, S. Serviços compartilhados como melhor prática. São Paulo: IBM Global Business Services, 2006. Disponível em: 
<http://www.ibm.com.br/services/articles/2006/10/a31m004t11s032006.shtml>. Acesso em: 17 maio 2014

MARTINS. V.; AMARAL, F. A consolidação da prática de serviços compartilhados. Egesta, V. 4, n. 1, p. 158-189, 2008.

PEREIRA, N. Impactos da implantação do Centro de Serviços Compartilhados sobre Sistemas de Controles: estudo de caso. 2004. Dissertação (Mestrado em Administração) Pontifícia Universidade Católica do Paraná, Curitiba, PR, Brasil, 2004.

PORTULHAK, H.; ESPEJO, M. M. S. B.; GARCIAS, P. M.; MARTINS, D. B. Papéis, responsabilidades e desafios na implantação e na manutenção de Centro de Serviços Compartilhados: uma análise empírica em uma multinacional instalada no Brasil. Revista Iberoamericana de Contabilidad de Gestión, v. 11, n. 22, p. 1-16, 2013.

QUINN, B.; COOKE, R.; KRIS, A. Shares services: mining for corporate gold. London: Financial Times Prentice Hall, 2000.

RAMOS, L. Serviços compartilhados como forma de estruturação organizacional. 2005. 128 fls. Dissertação (Mestrado em Administração) - Universidade Federal da Bahia, Salvador, BA, Brasil, 2005.

SCHULMAN, D.; HARMER, M.; DUNLEAVY, J. Shared services: adding value to the business units. John Wiley \& Sons Inc., 1999.

SHULZ, V.; BRENER, W. Characteristic Shared Service Centers. Transforming Government: People, Process and Police, v. 4, n. 3, p. 210-219, 2010.

SOUZA, R. Uma reflexão acerca da construção de conhecimento na investigação do ensino de línguas. Estudos Anglo-Americanos, v. 1, n. 29/30, p. 163-184, 2006.

SUM, F.; PAULA, I. Definição de diretrizes para o business case para implantação de um CSC. 2011. Disponível em:

<http://www.lume.ufrgs.br/bitstream/handle/10183/33179/000787437.pdf?sequence=1> . Acesso em: 17 maio 2014.

YIN, R. Estudo de caso: planejamento e métodos. 2. ed. Porto Alegre: Bookman, 2001. 